\title{
Site-Specific Specimen Preparation by Focused Ion Beam Milling for Transmission Electron Microscopy of Metal Matrix Composites
}

\author{
Philippe Gasser, ${ }^{1}$ Ulrich E. Klotz, ${ }^{1, *}$ Fazal A. Khalid, ${ }^{2}$ and Olivier Beffort ${ }^{3}$ \\ 'Swiss Federal Institute for Materials Testing and Research (EMPA), Ueberlandstrasse 129, CH-8600 Duebendorf, Switzorland \\ Fatulty of Metnllurgy and Materials Enyineering, Gulam Ishaq Khan Institule of Engineering Sciences and Technology, \\ Topi, North-West Frontier Province, Pakistan \\ ${ }^{3}$ Swiss Federal Jnstitute for Materials Testing and Research (EMPA), Fenerwerkerstrasse 39, CH-3602 Thum, Switzerland
}

\begin{abstract}
This work describes the application and usefulness of the focused ion beam (FIB) technique for the preparation of transmission electron microscopy (TEM) samples from metal matrix composite materials. Results on an $\mathrm{Al} /$ diamond composite, manufactured by the squeeze casting infiltration process, were chosen for demonstration. It is alnost impossible to prepare TEM specimens of this material by any other conventional method owing to the presence of highly inhomogeneous phases and reinforcement diamond particles. The present article gives a detailed account of the salient features of the FIB technique and its operation. One of the big advantages is the possibility to prepare site-specific TEM specimens with high spatial resolution. The artifacts occurring during the specimen preparation, for example, Ga-ion implantation, curtain effects, amorphous layers, bending of the lamella, or different milling behaviors of the materials have been discussed. Furthermore, TEM examination of the specimens prepared revealed an ultrafine amorphous layer of graphite formed at the interface between the $\mathrm{Al}$ and diamond particles that nay affect the interfacial properties of the composite materials. This may not have been feasible without the successful application of the FIB technique for production of good quality site-specific TEM specimens.
\end{abstract}

Key words: focused ion beam (FIB), transmission electron microscopy (TEM), alunimum, diamond, microstructure, interface

\section{INTRODUCTION}

The focused ion beam (FIB) lift-out technique has been established as a standard transmission electron microscopy (TEM) sample preparation technique for silicon wafers and has been frequently described in detail in several publications (Giannuzzi et al., 1998, 1999; Lipp, 1998; Engelmann et al., 2002). Recently, the FIB technique also gained interest in other fields of science for the preparation of TEM samples (Lomness et al., 2001; White et al., 2001; Klotz et al., 2002). Up to now several different methods of TEM sample preparation by means of $\mathrm{FIB}$ have been proposed and reviewed critically by Giannuzzi and Stevie (1999), Kim and Dravid (2000), and Anderson (2002). However, the application of the FIB technique for the preparation of TEM samples from difficult-to-machine hard phase reinforced "soft" metals, such as metal matrix composites (MMCs), has hardly been reported so far. Typical examples of MMCs that have been prepared for TEM. investigation by means

Received December 17, 2002; accepted September 17, 2003

*Corresponding author. E-mail: ulrich.klotz@empa.ch of FIB at EMPA so far are Al/Diamond, Al/C60 (Khalid et al., 2002), $\mathrm{Al} / \mathrm{SiC}, \mathrm{Ni} / \mathrm{Al}_{2} \mathrm{O}_{3}$, and $\mathrm{Cl} / \mathrm{SiO}_{2}$ metal matrix composites.

A considerable advantage of the FIB technique conpared to classic TEM sample preparation methods is the possibility to take out TEM samples at a local site of interest. This is of great importance for composite materials, because interesting features such as interfacial reactions often occur only locally. Therefore, one or more samples can be taken out at different sites of interest visible in the scanning electron microscope (SEM) inage. The following outline describes particular problems related to the preparation of TEM-lamellae from metal matrix composites by FIB, as illustrated for a virtually nonmachinable Al-diamond composite.

Diamond-based MMCs are expected to feature outstanding thermal conductivity along with a low CTE (coefficient of thermal expansion) and high elastic modulus. There is a need for such materials in power electronics where miniaturization leads to dramatically increasing power density along with excessive heat generation (i.e., IGBT [Insulated gate bipolar transistor] modules); very high heat fuxes have to be removed most efficiently. For such applications, diamond-based MMCs may be used as heat sinks and 


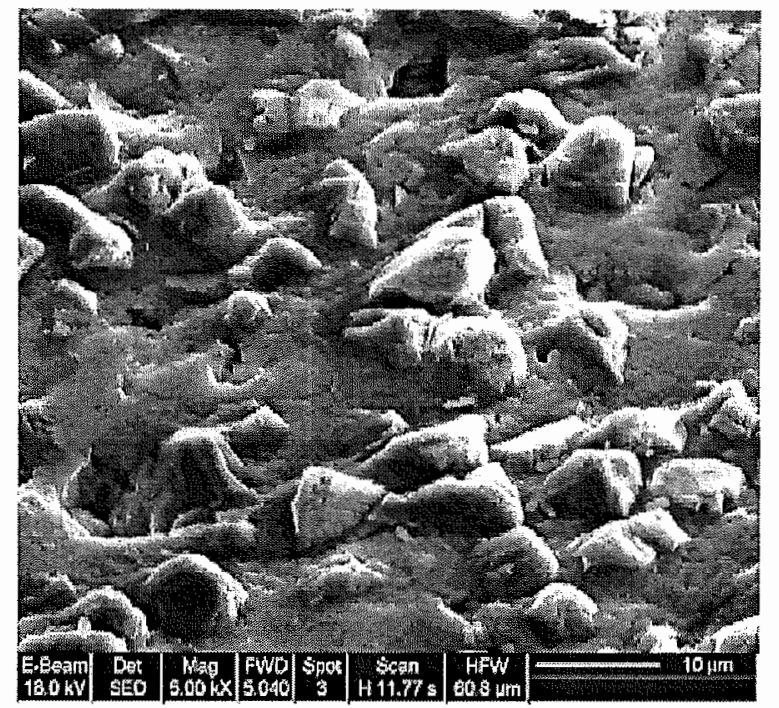

Figure 1. FEG-SEM micrograph of the Al-diamond sample. The diamond particles are protruding from the sample surface.

packaging materials. On the other hand, these materials are attractive for use in optical guidance systems where absolute form stability is a prerequisite for a proper performance; due to the aforementioned properties, diamond-based AlMMCs are expected to be far less sensitive to thermal distortion than other materials. In space applications (satellite mirror systems) the low density of the material would be an additional asset. The price of synthetic diamond grits is continuously coming down (about US\$0.15/ct.) and quality is strongly improving.

\section{Material and Methods}

\section{Material Processing}

Al-diamond composite samples were produced by squeeze casting infiltration using high purity (99.95\%) Al and monocrystalline synthetic diamond particles with a size of $10-$ $16 \mu \mathrm{m}$ (designation MSY 10-16) from Microdiamant, Switzerland. The as-received diamond powder was tappacked $(50 \mathrm{vol} \%)$ in a steel cylinder and preheated to $750^{\circ} \mathrm{C}$ in forming gas atmosphere ( $\mathrm{Ar} 94 \%+\mathrm{H}_{2} 6 \%$, to preclude oxidation) for $1 \mathrm{~h}$. Then, the compacted diamond powder was infiltrated with pressurized liquid aluminium that was superheated to $750^{\circ} \mathrm{C}$; subsequent solidification was achieved within less than $60 \mathrm{~s}$. After machining, the resulting composite specimens feature a cylindrical geometry with a diameter of $10 \mathrm{~mm}$ and a thickness of $5 \mathrm{~mm}$, and with a diameter of $3 \mathrm{~mm}$ and a thickness of $30 \mathrm{~mm}$. The samples were cut, ground, and polished using metallographic techniques. Because of their ultimate hardness, the diamond particles are protruding from the sample surface (Fig. 1).

\section{Results}

\section{TEM Sample Preparation by Focused Ion Beam Milling}

Samples for TEM investigation had been prepared with a FEI Strata DB 235 dual beam (DB) focused ion beam workstation directly from the ground and polished sample surface. The DB workstation incorporates a FIB and a SEM column tilted to each other by an angle of $52^{\circ}$. The operating principle of a focused ion beam machine is comparable to a SEM, but instead of electrons, a focused beam of $\mathrm{Ga}^{+}$ ions is scanned across the sample surface.

The SEM column is equipped with a FEG (field emission gun) emitter and an in lens detector. Resolution is specified to be $3 \mathrm{~nm}$ at $\mathrm{l} \mathrm{kV}$. The FIB column is adjustable from $1 \mathrm{pA}$ to $20,000 \mathrm{pA}$ at $30 \mathrm{kV}$ with a specified resolution of $7 \mathrm{~nm}$, as given by the manufacturer. The instrument is equipped with four secondary electron and ion detectors. The workstation has a digital patterning generator and four gas injection systems (GIS) for deposition and specific etching processes.

The TEM specimens were prepared by milling an electron-transparent sample (e.g., $20 \mu \mathrm{m}$ long, $5 \mu \mathrm{m}$ wide, and $100 \mathrm{~mm}$ thick) out of a bulk metallographic sample, including the Al-diamond interface region. The preparation consists of three main steps, which are described as follows and illustrated in Figure 2 and Figure 3.

\section{Selection of the Area of Interest and Prethinning}

First a platinum protection layer was deposited over the area of interest prior to ion milling, to protect the surface from ion damage. Then large stair-step trenches were milled on both sides of the metal deposition, and the remaining material was subsequently prethinned to a thickness of about $0.6 \mu \mathrm{m}$ (Fig. 2a).

\section{Milling Sequence and Parameters}

After the initial thinning, the stage was tilted by $52^{\circ}$ allowing us to cut off the sample at the bottom and both sides in such a way that only a small ligament remains on the both sides to fix the sample (Fig. 2b). This step is important to avoid mechanical strains in the sample, which can cause the lamella to bend after prolonged thinning. This point will be highlighted in greater detail in a following section.

Several thinning and polishing steps were performed to reduce the sample thickness to about $100 \mathrm{~nm}$. At the surface of the sample an amorphous layer is usually formed due to the bombarding with $\mathrm{Ga}^{+}$ions. The thickness of this layer was reduced in a last step. The typical operating parameters of the FIB at each stage are presented in Table 1.

\section{Cutting and Removal (Lift-Off) of the Specimen}

After the final polishing, the TEM lamella was completely cut off at the sides and the bulk sample was removed from 

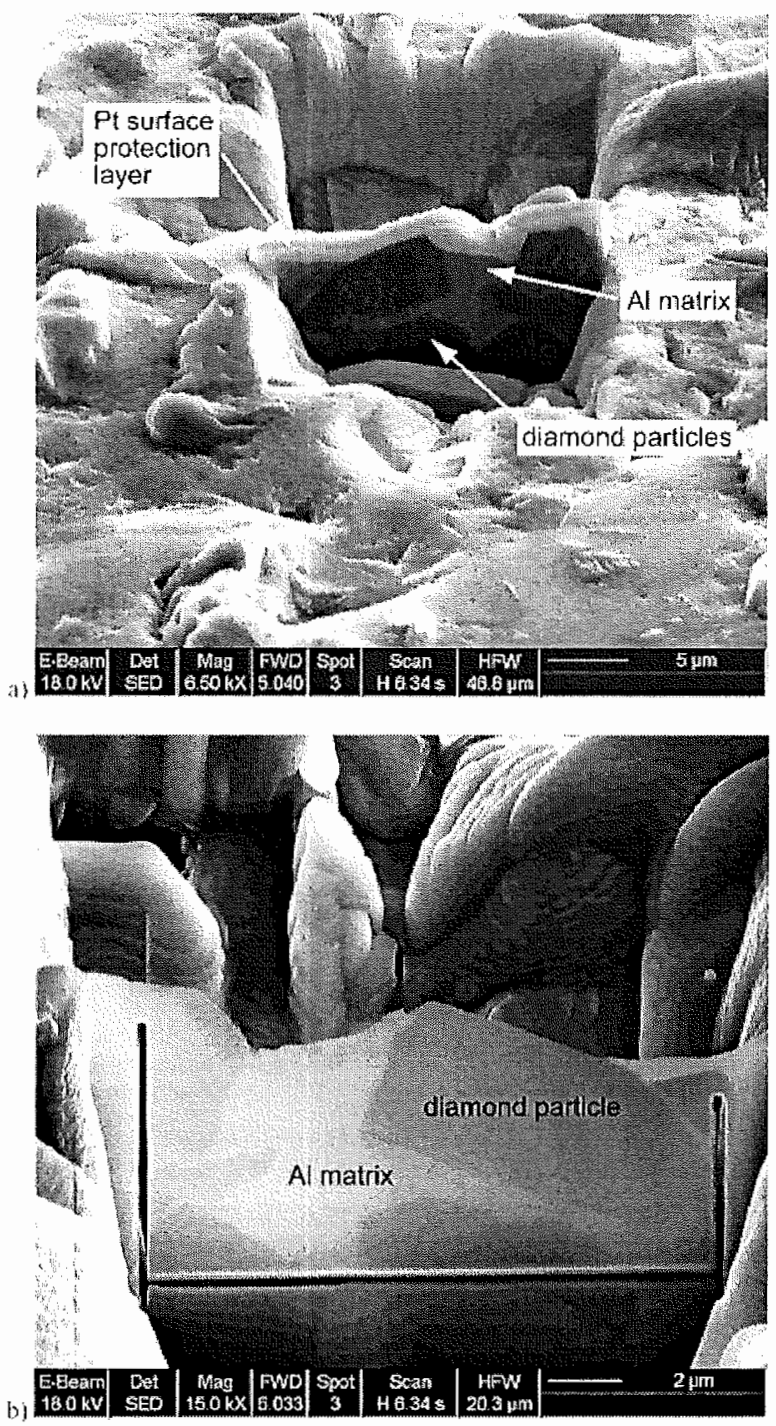

Figure 2. a, b: FEG-SEM innages showing stair-step trenches on both sides of the lamella formed at the initial and final stages of TEM sample preparation during the FIB milling operation.

the FIB instrument. It was placed under an ex situ optical microscope. A pneumatically driven micromanipulator arm with a glass rod attached was used to extract the sample onto a standard TEM grid for further TEM analysis (Fig. 3).

The lift-out process is impeded by a rough sample surface, as in the present case. This makes it difficult to focus the sample in the optical microscope. In situ lift-out in the FIB would ease this problem, because of the much higher depth of focus. It must also be said that lift-out of samples requires great operator skills. With some training, a successful lift-out of about $95 \%$ of all lamella prepared is being achieved.

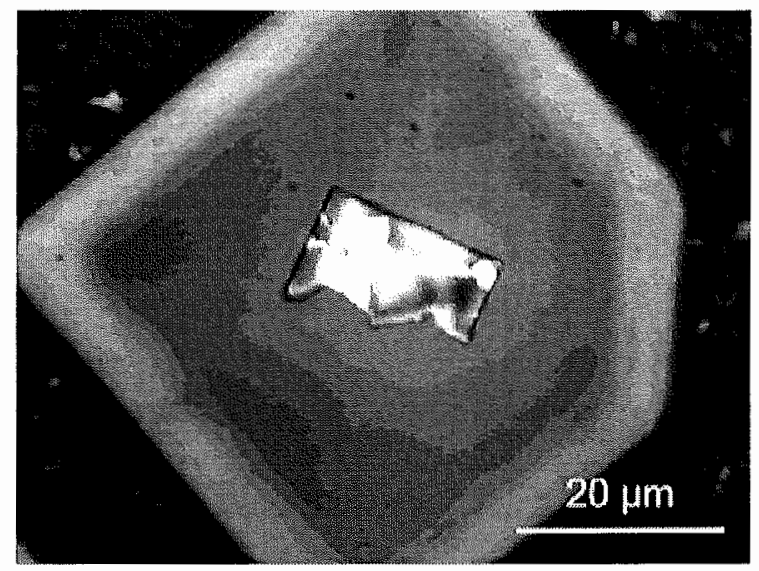

Figure 3. Optical micrograph of the TEM sample placed on a standard TEM grid ( 400 mesh) by a glass needle attached to an $e x$ situ nicromanipulator.

\section{TEM Study of Interfacial Structure}

Considering the theoretical chemical and thermodynamic instability of diamond in aluminum during high temperature liquid phase processing, it was of prime interest to investigate the integrity of the diamond particles in the aluminum matrix. Particular attention was paid to the Al-diamond interface, where chemical reactions or transformations are prone to occur. For this purpose, the sitespecific sample prepared by FIB as described in the previous paragraph was examined by TEM. The TEM investigation was made using a Philips CM30 (S)'TEM, working at an acceleration voltage of $300 \mathrm{kV}$.

Figure 4 shows characteristic features of the interfacial region between the $\mathrm{Al}$ matrix and a diamond particle. A fine dislocation substructure is observed in the Al matrix. The corresponding diamond particle exhibits a smooth-faceted morphology that compares to the as-received aspect of the diamond particles. Principally, the diamond particles in the

Table 1. Typical Focused Ion Beam Parameters Used for the Different Stages of TEM Sample Preparation

\begin{tabular}{|c|c|c|c|}
\hline Operation & $\begin{array}{l}\text { Acceleration } \\
\text { voltage } \\
(\mathrm{kV})\end{array}$ & $\begin{array}{l}\text { Probe } \\
\text { current } \\
(\mathrm{pA})\end{array}$ & $\begin{array}{l}\text { Duration } \\
\text { (min) }\end{array}$ \\
\hline Platinum deposition & E-beam, $3-5 \mathrm{kV}$ & Spot $5-7$ & 5 \\
\hline $\begin{array}{l}\text { Making a stair-step } \\
\text { trench }\end{array}$ & 1-beam, $30 \mathrm{kV}$ & $20,000-7000$ & 45 \\
\hline Prethinning & I-beam, $30 \mathrm{kV}$ & $3000-1000$ & 45 \\
\hline Final thinning & 1-beam, $30 \mathrm{kV}$ & $300-100$ & 120 \\
\hline \multicolumn{4}{|c|}{ Removing amorphous } \\
\hline layer & I-beam, $30 \mathrm{kV}$ & $60-70$ & 0.1 \\
\hline
\end{tabular}




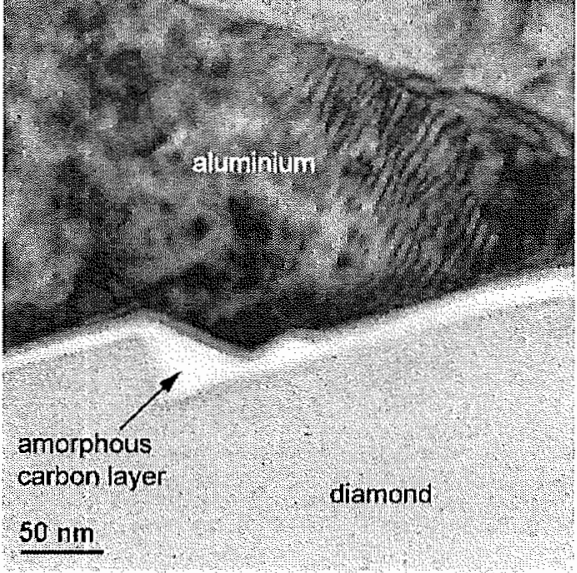

(a)

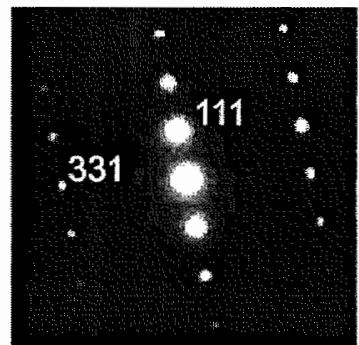

$Z=[123] A$

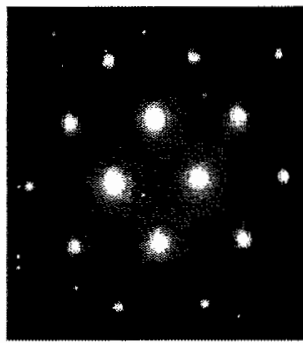

$Z=[011]$ diamond

(d)

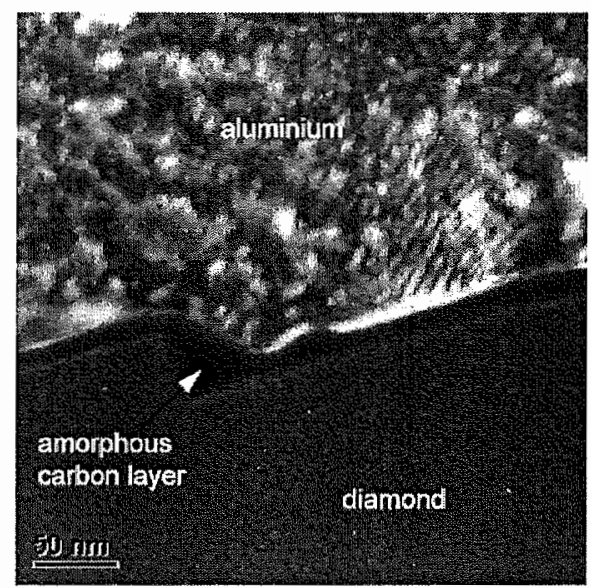

(b)

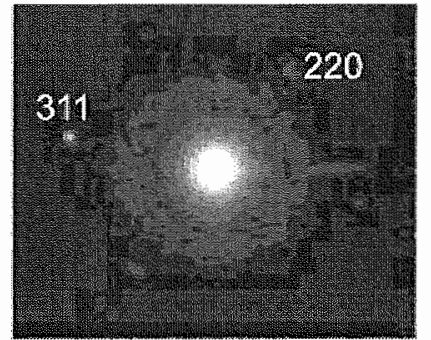

$\mathrm{Z}=[114]$ diamond

(c)

Figure 4. TEM micrographs showing the interfacial structure of the Al-diamond composite sample, (a) bright field, (b) dark field $\mathrm{Al}, \mathrm{g}=[111] \mathrm{Al}$, (c-e) SAD patterns from the $\mathrm{Al}$ matrix, diamond particle, and interface, respectively.

composite appear to be free of defects and the crystal structure is not degraded, as confirmed by selected area diffraction (SAD) analysis. Nonetheless, a thin layer of (amorphous) carbon with a thickness of a few nanometers was occasionally observed at the interface between the Al-matrix and the diamond particles, as shown in Figure 4. The presence of such an interfacial layer may affect the overall composite properties and can act as a precursor for the nucleation of $\mathrm{Al}_{3} \mathrm{C}_{4}$ precipitates, as reported in previous work (Khalid et al, 2003).

\section{Discussion}

\section{Artifacts and Problems Arising during the FIB Milling Operation}

\section{General Artifacts}

The susceptibility to artifacts is a general problem during TEM sample preparation. However, in the case of using a FIB, some specific problems arise.
During ion milling or imaging with the ion beam, the sample is scanned with $\mathrm{Ga}^{+}$ion beam. The $\mathrm{Ga}^{+}$ions are discharged due to the grounding of the sample material. Therefore, $\mathrm{Ga}$ is implanted in the sample surface. This has to taken into account in analytical microscopy, but does not generally affect the quality of the TEM images made in bright-field or dark-field mode. However, the bombardment of the sample with heavy and therefore highly energetic $\mathrm{Ga}^{+}$ions causes beam damage of the surface layer (several nanometers) of the material investigated, resulting in an amorphization.

To avoid these artifacts, generally, the imaging time with the ion beam should be kept as short as possible, and the bean current should be low. A reduction of the amorphization depth at each side of the lamella (and therefore better contrast in TEM analysis) can be achieved with the following final procedure applied: The ion-beam acceleration voltage is reduced from $30 \mathrm{kV}$ to $7 \mathrm{kV}$. A diaphragn for $300 \mathrm{pA}$ ion-beam current is used, which results in about $60 \mathrm{pA}$ at $7 \mathrm{kV}$. The lamella is tilted several degrees out of the ion beam axis $\left(4^{\circ}\right.$ to $\left.6^{\circ}\right)$. A fast scan time is applied on a 
selected area for about 6 to $8 \mathrm{~s}$, until a contrast change becomes visible. With this procedure the thickness of the amorphous layer can be reduced down to about $2 \mathrm{~nm}$ in the case of metallic samples (Engelmann et al., 2002).

Modification or damage of the surface layer can be avoided by precoating the bulk sample with a $50 \mathrm{~nm}$ layer of Au or Pt (Lipp, 1998). In the case of our Dual Beam workstation, the electron beam has been used for imaging as well as for the electron-beam-induced deposition of a $\mathrm{Pt}$ protection strip (Fig, 2i). The usage of the electron beam for $\mathrm{Pt}$ deposition will ensure that no damage of the surface region can occur.

\section{Artifacts for Metal Matrix Composites}

The preparation of metal matrix composites gives rise to additional artifacts due to the different physical and mechanical properties of the metallic and the ceramic parts. One specific problem is the very different sputtering rates of the materials involved, which affects the milling process. The stair-step trenches cannot be milled with one single box as the more resistant material needs up to five times more milling time than the "soft," metallic one. Therefore, the sample should preferably be prethinned down to $1 \mu \mathrm{m}$ with two boxes and different milling times or even different milling currents for the different materials. Beam currents of less then $300 \mathrm{pA}$, as typically required for the final thimning, result in a quite slow progress in the ceramic part (diamond, $\mathrm{Al}_{2} \mathrm{O}_{3}, \mathrm{SiC}$, etc.), for instance. Al-diamond composite materials tend to produce a distinctive curtain effect (see Fig. 2a), as the diamonds usually strongly resist the milling process compared to the matrix. To remove curtain effects and to avoid "shadowing," the ion beam current is reduced stepwise from $1000 \mathrm{pA}$ down to $100 \mathrm{pA}$ while the sample surface is being controlled regularly in the SEM mode. This final thinning procedure takes up to $2 \mathrm{~h}$ (see Table 1) and is necessary to obtain a smooth, thin sample. The $\mathrm{Pt}$ or $\mathrm{W}$ protection strip on the metallic part of the lamella should be made thick enough to prevent the metallic matrix from being milled away during final polishing, as long as the ceramic part is still not electron transparent

A second problem is bending of the sample caused by an accommodation of local residual stresses in the sample and the different physical and mechanical properties of metal and ceramic. Bending can occur in an axis parallel or vertical to the sample surface or in an axis with arbitrary orientation. It is usually not known if or on which axis bending will occur at a specific sample site. However, bending can make it very difficult to achieve a homogenous sample thickness.

Three different approaches have been used to reduce or even avoid bending. The first two techniques are useful if the sample starts to bend in an axis vertical to the sample surface. The bending stress in the lamella can be lowered by releasing the constraints on both sides of the lamella. The
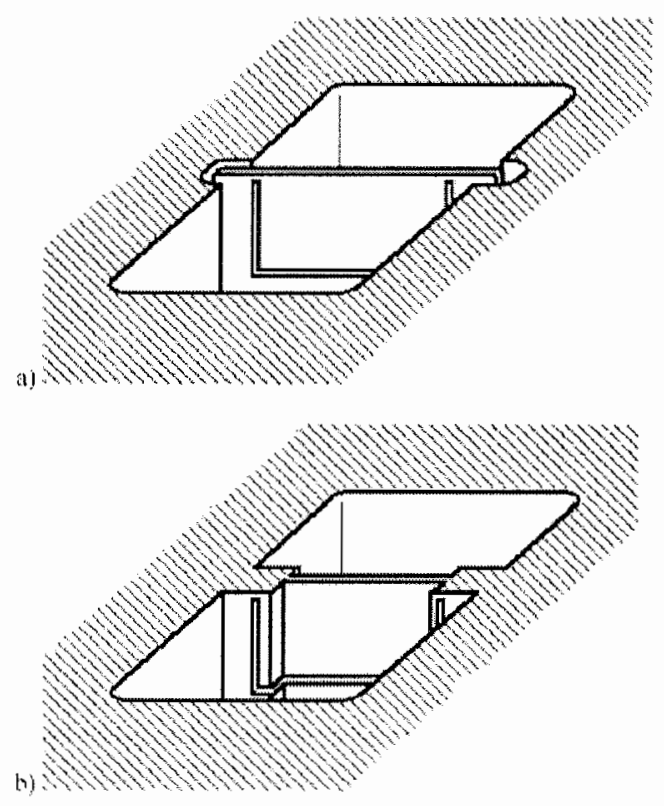

Figure 5. a, b: Sketches showing two possible methods to avoid bending of the TEM sample during FIB milling.

third technique is useful if bending occurs in an axis parallel to sample surface (this causes the sanple to "roll up") or an arbitrary orientation. This is therefore the most effective method in preventing bending.

1. After the lamella is cut underneath and is noticed to bend, the metal side of the sample may be cut off completely. This is done because it is usually the metal being deformed, whereas the ceramic is stable enough to allow the lanella to be polished. However, this can cause the lamella to vibrate during continued thinning.

2. Trenches on either side of the lamella can be used to release strain. They should be milled in an early stage with the stair-step trenches. As soon as the lamella is precut underneath and on both sides, only a thin pair of stalks should remain (see Fig. 5a). With this method, the lamella is still fixed at the top end and, therefore, no vibration occurs.

3. A type of "frame" can also be used to support the lamella. For this, the lamella should be precut after reaching a thickness of about $0.6 \mu \mathrm{m}$. Only the central part, and not-if possible-the full size of the lamella should then be thinned to electron transparency. The remaining frame should be thick enough to resist bending (see Fig. 5b). This is the most effective way to prevent bending around any axis.

Despite applying these techniques, some specimens still remain difficult to thin and therefore require a lavish preparation. 


\section{CONCLUSIONS}

The results of this study for the site-specific TEM specimen/ lamella preparation by means of focused ion beam (FIB) milling can be summarized as follows:

- The FIB milling technique has been very useful for the preparation of TEM samples from highly anisotropic Al-matrix composite material with hard diamond particles embedded. The method is site specific $(\approx 20 \mu \mathrm{m})$ and gives excellent results.

- FIB milling provides fast preparation and is a reliable method for composite materials, which allows the preparation of TEM lamella localized at the interface within about $4 \mathrm{~h}$. This is much quicker compared to classic preparation techniques. Unfortunately, the automization techniques used for semiconductor applications cannot be used here, due to anisotropic material properties.

- Typical artifacts in MMCs arise from residual stresses during manufacturing and the different physical and mechanical properties of the two materials. As a result, very different ion milling rates are observed for the metallic and the ceramic parts.

- The above mentioned effects may cause bending of the lamella and inhomogeneous sample thickness, which have to be avoided by special preparation techniques. Bending can be avoided by releasing the constraints on both sides of the lamella and supporting it in the vertical direction. The different milling rates have to be addressed by thinning both materials separately with different probe currents to achieve homogenous thickness.

- The TEM investigation revealed the high quality of the lamella prepared. The Al matrix and the diamond particles appeared to be free of defects or degradation. At the interface, a thin layer of amorphous carbon was observed, which may act as precursor for the nucleation of $\mathrm{Al}$ carbide precipitates.

\section{ACKNOWLEDGMENTS}

The authors thank Mr. Fred Schmid for assistance in preparation of the metallographic samples and Vincent Barnier for composite sample preparation and characterization.

\section{RefERENCES}

Anderson, R. (2002). Critical comparison of FIB TEM specimen preparation methods. In Proceedings of the 15th International Congress on Electron Microscopy, Engelbrecht, J., Sewell, T. Witcomb, M., Cross, R. \& Richards, P. (Eds.), pp. 253-254. Onderstepoort, South Africa: Microscopy Society of South Africa.

Englimann, H.J., Volkmann, B., SaAge, H., Stegmann, H., ZiEsche, S. \& ZSCHECH, E. (2002). TEM sample preparation using focused ion beam-Capabilities and limits. In Proceedings of the 15th International Congress on Electron Microscopy, Engelbrecht, J., Sewell, T., Witcomb, M., Cross, R. \& Richards, P. (Eds.), pp. 257-258. Onderstepoort, South Africa: Microscopy Society of South Africa.

Giannuzzi, L.A., Drown, J.I.., Brown, S.R, Irwin, R.B. \& Strvie, F.A. (1998). Applications of the FIB lift-out technique for TEM specimen preparation. Micros Res Tech 41, 285-290.

Glannuzzi, L.A. \& Srevie, FA. (1999). A review of focused ion beam milling techniques for TEM specimen preparation. $\mathrm{Mi}$ cron 30, 197-204.

Khald, F.A., BerforT, O., Kiotz, U.E., Keller, B., Gasser, P. \& Voucher, S. (2003). Study of microstructure and interfaces in an aluminium- $\mathrm{C}_{60}$ composite material. Acta Mat 51, 45754582 .

Kim, S.T. \& Dravid, V.P. (2000). Focused ion beam sample prepa ration of continuous fibre-reinforced ceramic composite specimens for transmission electron microscopy. I Microsc 198 , 124-133.

Klotz, U.E., Wilcock, I., Henderson, M.B. \& DAvis, S. (2002). Interdiffusion in HIPped bi-nuetallic turbine discs. In Proceedings of the 15th International Congress on Electron Microscopy, Engelbrecht, I., Sewell, T., Witcomb, M., Cross, R, \& Richards, P. (Eds.), pp. 693-694. Onderstepoort, South Africa: Microscopy Society of South Africa.

L.pp, S. (1998). Untersuchungen von Ätz- und Abscheideprozessen im fokusierten lonenstrahl. In Erlanger Berichte Mikroelektronik, Vol. 98/1, Aachen: Shaker.

Lomness, J.K., Giannuzzl, L.A. \& Hampton, M.D. (2001). Sitespecific transmission electron microscope characterization of micrometer-sized particles using the focused ion bean lift-out technique. Microsc Microanal 7, 418-423.

White, H., Pu, Y., Rafallovich, M., Sokolov, J., King, A.H. Giannuzzi, L.A., Urbanik-Shannon, C., Kempshall, B.W., EIsenberg, A., SCHWARz, S.A. \& StrzhemfChNy, Y.M. (2001). Focused ion beam/lift-out transmission electron microscopy cross sections of block copolymer films ordered on silicon substrates. Polynter 42, 1613-1619. 